\title{
Genetic Modification for Improving Seed Vigor Is Transitioning from Model Plants to Crop Plants
}

\author{
Xiaolin Wu, Fen Ning, Xiuli Hu and Wei Wang* \\ State Key Laboratory of Wheat and Maize Crop Science, Collaborative Innovation Center of Henan Grain Crops, College of \\ Life Sciences, Henan Agricultural University, Zhengzhou, China
}

\section{OPEN ACCESS}

Edited by:

Alma Balestrazzi,

University of Pavia, Italy

Reviewed by:

Hao Peng,

Washington State University, USA

Paola Leonetti,

National Research Council, Italy

${ }^{*}$ Correspondence:

Wei Wang

wangwei@henau.edu.cn

Specialty section:

This article was submitted to Crop Science and Horticulture,

a section of the journal

Frontiers in Plant Science

Received: 28 July 2016 Accepted: 03 January 2017 Published: 18 January 2017

Citation:

Wu $X$, Ning F, Hu X and Wang W (2017) Genetic Modification for Improving Seed Vigor Is

Transitioning from Model Plants to Crop Plants. Front. Plant Sci. 8:8.

doi: 10.3389/fpls.2017.00008
Although seed vigor is a complex physiological trait controlled by quantitative trait loci, technological advances in the laboratory are being translated into applications for enhancing seed vigor in crop plants. In this article, we summarize and discuss pioneering work in the genetic modification of seed vigor, especially through the over-expression of protein L-isoaspartyl methyltransferase (PIMT, EC 2.1.1.77) in seeds. The impressive success in improving rice seed vigor through the over-expression of PIMT provides a valuable reference for engineering high-vigor seeds for crop production. In recent decades, numerous genes/proteins associated with seed vigor have been identified. It is hoped that such potential candidates may be used in the development of genetically edited crops for a high and stable yield potential in crop production. This possibility is very valuable in the context of a changing climate and increasing world population.

Keywords: Arabidopsis, cereal crops, genetic modification, protein l-isoaspartyl methyltransferase (PIMT), rice, reactive oxygen species (ROS), seed vigor and longevity, transgenic seeds

\section{INTRODUCTION}

Seed vigor is a complex physiological trait that is necessary to ensure the rapid and uniform emergence of plants in the field (Ventura et al., 2012), essentially including the seed longevity, the tolerance of environmental stresses by germination, and the ability to withstand prolonged storage and CDT. This trait is controlled by many QTLs that are located on different chromosomes, as found in the model plant Arabidopsis (Clerkx et al., 2004) and in crop plants such as rice (Cui et al., 2002; Miura et al., 2002), Medicago truncatula (Vandecasteele et al., 2011), and maize (Han et al., 2014) and is also affected by environmental factors during seed development, harvest, and storage.

Orthodox seeds, such as cereal seeds, undergo desiccation at the end of the maturation process on the mother plant and maintain their vigor over prolonged time periods (Rajjou et al., 2012). Because of their desiccation tolerance during dry storage, orthodox seeds are most commonly used in agriculture. For example, only three crop species (wheat, rice, and maize) account for more than $50 \%$ of all calories consumed by of the global population (Macovei et al., 2012). In addition to economic and ecological importance, high-vigor seeds are necessary for seedling establishment and sustainable crop productivity, especially under unfavorable conditions

\footnotetext{
Abbreviations: CDT, controlled deterioration test; GABA, $\gamma$-aminobutyric acid; GM, genetic modification; HSF, heat stress transcription factor; HSPs, heat shock proteins; isoAsp, L-isoaspartyl residues; LEA, late embryogenesis abundant; OsALDH7, rice aldehyde dehydrogenase 7; OsPIMT1, rice protein l-isoaspartyl methyltransferase; PIMT, protein l-isoaspartyl methyltransferase; PLD, phospholipase; QTLs, quantitative trait loci; ROS, reactive oxygen species; SSADH, succinicsemialdehyde dehydrogenase.
} 
(Rajjou et al., 2012; Ventura et al., 2012). High-vigor seeds can improve seed germination and seedling emergence, increase crop yield and reduce the cost of agriculture production. With the widespread application of modern mechanized precision sowing technology for grain (e.g., maize, wheat) production, highvigor seeds have become particularly important. In addition, for seed germplasms conserved in gene banks around the world, seed vigor and longevity may affect the regeneration cycle of accessions stored in seed banks. Seeds in long-term storage, especially under high-temperature and high-moisture conditions, will eventually lose their viability (Ventura et al., 2012). High-vigor seeds can survive a prolonged storage time.

However, the seed vigor trait is often excluded from traditional breeding programs, which are mostly directed toward high yield. To increase the vigor of commercial seed lots, the seed industry practices various invigoration treatments, especially physical priming methods (review in Ventura et al., 2012; Araújo et al., 2016). In fact, the potential of GM technology for enhancing seed vigor has been proposed as the most effective, economical and sustainable approach (Clerkx et al., 2004; Vandecasteele et al., 2011; Han et al., 2014). In the context of classical breeding, the application of GM technology to agriculturally important crops will play an increasingly important role in solving some fundamental challenges that face agriculture, natural resources and the environment. In this article, we summarize and discuss some pioneering work in the GM of seed vigor, especially through the approach of genetic engineering the PIMT (EC 2.1.1.77) in seeds. GM for improving seed vigor is just transitioning from model plants to crop plants. Promisingly, numerous genes/proteins associated with seed vigor, identified over the decades, may be used for the creation of genetically edited crops for a high and stable yield potential in crop production. This possibility is very valuable in the context of a changing climate and increasing world population.

\section{PHYSIOLOGICAL, BIOCHEMICAL, AND GENETIC BASES OF SEED VIGOR}

Seed vigor is a complex physiological trait involving regulatory networks that integrate genetic programs, metabolic signals, and hormonal signaling pathways (Rajjou et al., 2012). Many QTLs located on different chromosomes have documented associations with seed vigor. The various candidate genes identified within these QTLs are mainly involved in the glycolytic pathway, protein metabolism and signal transduction (Cui et al., 2002; Miura et al., 2002; Vandecasteele et al., 2011; Han et al., 2014). Seed vigor also has a close relationship with seed maturity degree, harvest time, and storage period: it has a maximum at physiological maturity and then decreases during storage (Sun et al., 2007). Carbohydrates, proteins, and mRNAs stored during seed development on the mother plant assist with hormone signaling pathways, especially the ABA signaling pathway, to regulate seed germination and influence seed vigor (Rajjou et al., 2012). ABA participates in regulating the expression of some seed genes in the mother plant during seed dehydration, such as LEA proteins, and inhibits the germination of developing seeds (Williams and Tsang, 1991). During storage, the seed will always deteriorate through a series of changes, such as the accumulation of ROS, lipid peroxidation, loss of cellular membrane integrity, enzyme inactivation, weak energy metabolism, and DNA degradation (Kibinza et al., 2006; Parkhey et al., 2012; Ventura et al., 2012; Xin et al., 2014; Yin et al., 2014; Kong et al., 2015; Ratajczak et al., 2015).

The loss of seed vigor is a complex normal biological phenomenon. In research on the mechanism of seed vigor change, CDT is the main way to simulate the seed aging process because aging naturally is time-consuming. Proteomics analysis displays a similar proteome characterization between artificial and natural aged Arabidopsis seed (Rajjou et al., 2008). However, a recent study reported substantial differences in scutellum nuclear content and morphology between the viability loss of accelerated and naturally aged wheat seed (Ahmed et al., 2016). Numerous studies have been performed on the process of seed deterioration in various plant species (e.g., Catusse et al., 2008, 2011; Galpaz and Reymond, 2010; Han et al., 2014; Nagel et al., 2014). However, the underlying mechanism remains unclear. It has become increasingly accepted that ROS damage to DNA (Vanderauwera et al., 2011), proteins (Rajjou et al., 2008) and membrane lipids (Roqueiro et al., 2010) plays a role in seed aging. ROS are continuously generated during seed development, storage and germination and exist in a state of dynamic equilibrium in cells under the action of free radical scavenger enzymes. Thus, the accumulation of ROS could be a common mechanism in seed deterioration. As a countermeasure, seed vigor has evolved a sophisticated mechanism (protection, detoxification, and repair) to protect macromolecules from ROS damage (review in Rajjou et al., 2012; Ventura et al., 2012). The possibility of restricting ROS accumulation may be a promising step toward successfully engineering seed vigor in crops.

\section{POTENTIAL CANDIDATES OF GENES/PROTEINS ASSOCIATED WITH SEED VIGOR TRAIT}

Under natural conditions, it is very rare to acquire high-vigor seeds through natural variation. Traditional breeding has made great progress in crop improvement; however, the process is time-consuming, and the genetic resources regarding seed vigor are limited. Promisingly, with the development of global omics approaches, such as genomics, transcriptomics and proteomics, numerous potential candidates (genes/proteins) involved in seed vigor have been identified with high efficiency in recent decades (Table 1), though few have been detected in the identified QTLs associated with seed vigor (Cui et al., 2002; Miura et al., 2002; Vandecasteele et al., 2011; Han et al., 2014). These potential candidates may be used in breeding programs and/or in biotechnological approaches to improve seed vigor and crop yields. 
TABLE 1 | Candidate proteins/genes for improving seed vigor in plants.

\begin{tabular}{|c|c|c|}
\hline Plant species & Target proteins/genes & Reference \\
\hline \multicolumn{3}{|l|}{ Repair proteins/genes } \\
\hline Arabidopsis thaliana & AtLIG6, AtLIG4, AtOGG1 & Waterworth et al., 2010; Chen et al., 2012 \\
\hline Medicago truncatula & MSR, MtOGG1, MtFPG, MtTFIIS & Macovei et al., 2011a,b; Châtelain et al., 2013 \\
\hline \multicolumn{3}{|l|}{ Protective proteins/genes } \\
\hline A. thaliana & $\begin{array}{l}\text { ATEM6, PLD } \alpha 1 \text {, LEA14, XERO1, RAB18, HSP70, HSP 20, } \\
\text { HSP17.7 }\end{array}$ & $\begin{array}{l}\text { Gallardo et al., 2001; Manfre et al., 2006, 2009; Devaiah } \\
\text { et al., 2007; Hundertmark et al., } 2011\end{array}$ \\
\hline Oriza sativa & OsHSP18.2 & Kaur et al., 2015 \\
\hline Triticum aestivum & HSPs & Helm et al., 1989 \\
\hline Zea mays & $\begin{array}{l}\text { HSP18, HSP 17.2, HSP 16.9, LEA-3, EMB564, PR2, } \\
\text { Opaque2, MT1 }\end{array}$ & Revilla et al., 2009; Wu et al., 2011 \\
\hline Glycine max & $P L D \alpha$ & Lee et al., 2012 \\
\hline Helianthus annuus & HaHSFA9 & Prieto-Dapena et al., 2006 \\
\hline Nelumbo nucifera & NnHSP17.5 & Zhou et al., $2012 \mathrm{a}$ \\
\hline Beta vulgaris & HSP17, PP2A, 14-3-3, Glycine betaine & Catusse et al., 2008, 2011 \\
\hline M. truncatula & HSP 18.2, HSP17.4, GroEL, RPN1, sHSP20 & Yacoubi et al., 2011; Châtelain et al., 2012 \\
\hline \multicolumn{3}{|c|}{ Detoxification proteins/genes } \\
\hline A. thaliana & $\begin{array}{l}\text { SSADH, MSD1, CAT1, HPT1, APX4, AtDLAH, RBOH-B, } \\
\text { MST, VTE }\end{array}$ & $\begin{array}{l}\text { Bouché et al., 2003; Sattler et al., 2004; Rajjou et al., 2008; } \\
\text { Müller et al., 2009; Xi et al., 2010; Seo et al., 2011; Wang } \\
\text { et al., } 2014\end{array}$ \\
\hline O. sativa & OsALDH7, ACCase, PI3K & $\begin{array}{l}\text { Shin et al., 2009; Talai and Sen-Mandi, 2010; Liu et al., } \\
2012\end{array}$ \\
\hline Hordeum vulgare & PER1 & Stacy et al., 1999 \\
\hline Z. mays & 2-Cys Prx BAS1, TPX, GST, GLO, SOD4, CAT3 & Revilla et al., 2009; Wu et al., 2011 \\
\hline N. nucifera & NnANN1, NnMT2a, NnMT2b, NnMT3 & Chu et al., 2012; Zhou et al., 2012b \\
\hline Nicotiana tabacum & CUZnSOD, APX & Lee et al., 2010 \\
\hline M. truncatula & Annexin, SOD, Trx, AhpC, 1-Cys Prx, GST, Prx, MSR & Yacoubi et al., 2011, 2013; Châtelain et al., 2013 \\
\hline \multicolumn{3}{|l|}{ Others } \\
\hline A. thaliana & elFiso4F, RSL1, Gln1, Gln2 & Lellis et al., 2010; Bueso et al., 2014; Guan et al., 2015 \\
\hline Beta vulgaris & ICL, SAM, Cys synthase, caleosin & Catusse et al., 2008, 2011 \\
\hline G. $\max$ & Tu1, Tu2, 1-a & Wang et al., 2012 \\
\hline O. sativa & OSLOX & Suzuki and Matsukura, 1997; Wang et al., 2008 \\
\hline
\end{tabular}

\section{Repair Proteins}

The formation of isoAsp, arising from both the deamidation of L-asparaginyl residues and the isomerization of L-aspartyl residues, is a frequent chemical modification that alters protein structure and leads to a loss of function (Lowenson and Clarke, 1992). The PIMT counteracts such damage by catalyzing the conversion of isoAsp to normal Asp in a variety of organisms, including plants (reviewed in Clarke, 2003). The PIMT-mediated protein repair mechanism represents a good example that has been successfully engineered for enhanced seed vigor (see below: case of PIMT, Table 2). For orthodox seeds, DNA damage, caused by ROS stress, occurs during seed dehydration and storage, leading to vigor loss. It is generally recognized that enhanced seed vigor and successful priming depend on DNA repair mechanisms activated during imbibition (Ventura et al., 2012). In Arabidopsis, the plant-specific DNA ligase VI (AtLIG6 and AtLIG4) is an important determinant of seed vigor and longevity under adverse germination conditions; atlig6 and atlig6::atlig4 mutants show significant hypersensitivity to CDT, displaying delayed germination and reduced seed vigor (Waterworth et al., 2010). A bifunctional DNA glycosylase/apurinic/apyrimidinic lyase,
AtOGG1, is involved in base excision repair for eliminating 8-oxo-G from DNA, and the over-expression of AtOGG1 enhances seed longevity and abiotic stress tolerance (Chen et al., 2012). These DNA repair pathways represent potential targets for the generation of crops with improved seed vigor traits.

\section{Protective Proteins}

Protective molecules such as LEA proteins and HSPs are generally associated with desiccation tolerance and longevity and are accumulated in the maturation phase during seed development. These stress-related proteins may also play a role in seed vigor.

Transgenic Arabidopsis seeds over-accumulating a HSF exhibit enhanced accumulation of HSPs and improved tolerance to aging (Prieto-Dapena et al., 2006). Knockout mutation in ATEM6 of the Arabidopsis group 1 LEA family resulted in a premature phenotype, demonstrating that ATEM6 protein is associated with water retention/loss during seed maturation; however, it might not be required in mature seeds for viability or efficient germination (Manfre et al., 2006, 2009). Dehydrins are LEA proteins that accumulate during seed maturation and in response to abiotic stresses 
TABLE 2 | Physiological consequences of altering PIMT accumulation in plant seeds.

\begin{tabular}{|c|c|c|c|}
\hline Plant species & Methodology & Main findings and altered seed traits & Reference \\
\hline A. thaliana & $\begin{array}{l}\text { T-DNA insertion line with increased } \\
\text { PIMT1 expression and transgenic lines } \\
\text { with altered PIMT1 expression }\end{array}$ & $\begin{array}{l}\text { The physiological role of AtPIMT1 in seed vigor and longevity has been } \\
\text { established in Arabidopsis. } \\
\text { The higher PIMT1 amount in pimt1-1 seeds correlates with lower } \\
\text { isoAsp accumulation in vivo and increases both seed longevity and } \\
\text { germination vigor, and vice versa. } \\
\text { Germination \% after } 8 \text { days storage }\left(40^{\circ} \mathrm{C}, 15-20 \% \text { humidity): } 52 \text { and }\right. \\
25 \% \text { for WT seeds; } 80 \text { and } 50 \% \text { for the pimt1-1 mutant seeds, } \\
\text { monitored at } 4 \text { days after sowing. }\end{array}$ & Ogé et al., 2008 \\
\hline Cicer arietinum & $\begin{array}{l}\text { Seed-specific Over-expression of } \\
\text { CaPIMT1 and CaPIMT2 in Arabidopsis }\end{array}$ & $\begin{array}{l}\text { The role of CaPIMT2 in seed vigor and longevity has been elucidated. } \\
\text { CaPIMT2 enhances seed vigor and longevity by repairing abnormal } \\
\text { isoAsp in the seed nuclear proteome. } \\
\text { Germination \% after } 4 \text { days of CDT, control seeds, } 10-14 \% \text {; CaPIMT1 } \\
\text { and CaPIMT2 transformed seeds, } 80-90 \% \text {. }\end{array}$ & Verma et al., 2013 \\
\hline \multirow[t]{2}{*}{ O. sativa } & $\begin{array}{l}\text { Overexpressing OsPIMT1 lines and } \\
\text { OsPIMT1 RNAi lines }\end{array}$ & $\begin{array}{l}\text { The role of OsPIMT1 in seed vigor and longevity has been elucidated. } \\
\text { Germination \% after } 21 \text { days of CDT, overexpressing OsPIMT1 } \\
\text { transgenic seeds, increased 9-15\%; OsPIMT1 RNAi lines, rapid loss of } \\
\text { germination. }\end{array}$ & Wei et al., 2015 \\
\hline & $\begin{array}{l}\text { Transgenic rice and Arabidopsis lines } \\
\text { with altered expression of OsPIMT1 } \\
\text { and OsPIMT2 }\end{array}$ & $\begin{array}{l}\text { The PIMT-mediated protein repair mechanism during seed development } \\
\text { and aging in rice has been elucidated, i.e., OsPIMTs repairs } \\
\text { antioxidative enzymes and proteins that restrict ROS accumulation, lipid } \\
\text { peroxidation, and so on, thus contributing to seed vigor and longevity. } \\
\text { Transgenic rice overexpressing OsPIMT1 and OsPIMT2 exhibits } \\
\text { improved seed vigor and longevity. } \\
\text { Germination \% after } 4 \text { days of CDT, control seeds, } 8 \% \text { (maximum); } \\
\text { OsPIMT1, OsPIMT2, and } \triangle \text { OSPIMT2 transformed seeds, 43-48\%. }\end{array}$ & Petla et al., 2016 \\
\hline
\end{tabular}

in vegetative tissues. A twofold reduction in seed-specific dehydrin (LEA14, XERO1, and RAB18) by RNAi reduced seed longevity and viability in Arabidopsis (Hundertmark et al., 2011). Phospholipase D, which cleaves phospholipids and generates phosphatidic acid (PA), is involved in the early stages of seed deterioration. The accumulation of PA in seeds triggers damage at the level of cellular membranes and storage lipids. Depletion of the Arabidopsis PLD $\alpha 1$ gene, encoding a member of the lipid-hydrolyzing phospholipase D family, resulted in seeds with lower levels of lipid peroxides and increased tolerance to aging (Devaiah et al., 2007).

\section{Detoxification Proteins}

This class of proteins performs the degradation and/or elimination of endogenous and exogenous toxins, such as ROS. In particular, to eliminate ROS, cells develop a number of ROS scavengers such as superoxide dismutase, peroxidase, and vitamins. Enhanced seed longevity has been reported through the elimination of ROS by over-accumulated ROS scavengers in transgenic seeds (e.g., Lee et al., 2010).

Three genes (NnMT2a, NnMT2b, and NnMT3) from sacred lotus that encode metallothioneins, cysteine-rich small proteins involved in ROS scavenging, were highly expressed in germinating sacred lotus seeds and dramatically upregulated in response to high salinity and oxidative stresses (Zhou et al., 2012b). Moreover, transgenic Arabidopsis seeds overexpressing NnMT2a and NnMT3 displayed a remarkably improved resistance to accelerated aging treatment, indicating their significant roles in seed germination vigor (Zhou et al., 2012b).
The mitochondrial SSADH is one of the three enzymes involved in the GABA shunt. In plants, the role of the GABA shunt in protection against oxidative stress has been demonstrated (Bouché et al., 2003). The presence of SSADH in dry seeds suggests that the GABA shunt is involved in the control of seed longevity or/and germination. Mutations in the OsALDH7 gene resulted in seeds that were more sensitive to artificial aging conditions and accumulated more malondialdehyde than wild-type seeds, implying that this enzyme plays a role in maintaining seed viability by detoxifying the aldehydes generated by lipid peroxidation (Shin et al., 2009).

\section{GENETIC MODIFIED SEEDS FOR ENHANCED VIGOR: CASE OF PIMT}

In seeds, proteins are prone to aging damage during normal aging and CDT. To date, a successful approach to enhanced seed vigor involves enhancing the accumulation of PIMT in seeds. However, no specific proteins have been assigned to the identified QTLs associated with seed vigor. The history of this effort provides an excellent example of how scientific problem solving can be brought to bear on applications in agriculture.

Mudgett and Clarke (1993, 1994) first discovered PIMT activity in plants and proposed that PIMT might be involved in seed survival by preventing isoAsp accumulation in the proteins of aging and stressed seeds. PIMT has since been detected in a wide range of plants and cloned in Arabidopsis, wheat, chickpea and rice, and the numbers are still increasing. In plants, PIMT is encoded by two different genes (PIMT1 and PIMT2) (Xu et al., 2004), which display distinct expression 
patterns but similar biochemical properties (Thapar et al., 2001). Later, Ogé et al. (2008) validated the role of this enzyme in both seed vigor and longevity by altering the expression of PIMT1 in Arabidopsis. Their findings implicate PIMT1 as a major endogenous factor that limits isoAsp accumulation in seed proteins, thereby improving seed traits such as longevity and vigor. Recently, the role of PIMT in seed vigor and longevity has been evaluated in chickpea (Cicer arietinum) (Verma et al., 2013) and rice (Oriza sativa) (Wei et al., 2015; Petla et al., 2016). Notably, transgenic rice constitutively overexpressing OsPIMT1 and OsPIMT2 exhibited improved seed vigor and longevity (Petla et al., 2016).

Although the seed vigor trait depends on a wide range of physical, chemical, molecular and QTLs, the PIMT repair pathway improves seed vigor in rice by restricting the formation of deleterious isoAsp and repairing damaged proteins, not through direct DNA or lipid protection (Petla et al., 2016). This finding implies the efficacy of making high-vigor rice seeds through a target-gene approach. However, it remains to be observed whether this approach can work in the field or whether other single-gene manipulations can also produce such effects. Moreover, the effect of enhanced PIMT expression on other seed traits, e.g., nutrient value, potential health risk as food and feed, and plant phenotypes, must be extensively evaluated. In addition, the exploitation of such PIMT-mediated improvement of seed vigor in other important crops could have a huge impact on the agricultural economy. The successful case of over-expressed PIMT enhancing seed vigor proves a good guide for other potential candidates.

\section{CONCLUDING REMARKS AND PERSPECTIVE}

Currently, achieving food supply security with limited arable land is a major global challenge due to the changing climate and increasing global population. The approach of modifying PIMT in seed tissues provides a rational means of creating high-vigor seeds for crop production. Its application to important cereals such as wheat, rice, and maize may have a dramatic impact on global food security. Despite substantial progress, many questions still remain. The possible effect of enhanced seed vigor obtained by the over-expression of PIMT and other proteins on the nutritional value of crops is unclear. It remains to be assessed whether a GM seed with enhanced vigor shares similar health and nutritional characteristics with its conventional counterpart.

\section{REFERENCES}

Ahmed, Z., Yang, H., and Fu, Y. (2016). The associative changes in scutellum nuclear content and morphology with viability loss of naturally aged and accelerated aging wheat (Triticum aestivum) seeds. Front. Plant Sci. 7:1474. doi: $10.3389 /$ fpls.2016.01474

Araki, M., and Ishii, T. (2015). Towards social acceptance of plant breeding by genome editing. Trends Plant Sci. 20, 145-149. doi: 10.1016/j.tplants.2015. 01.010
While numerous potential candidates (genes/proteins) associated with seed vigor are available, their roles in improving seed vigor must be validated by reverse genetics on large-scale samples before translation into application in agriculturally relevant crop species. The rapid development of new genomeediting techniques enables the precise modulation of traits of interest with unprecedented control and efficiency. Among the current genome-editing tools, CRISPR is easy, rapid and inexpensive, exhibiting a broad applicability of plant genome editing for the development of designer crops (review in Khatodia et al., 2016). However, it is important to remember that the safe use of GM food or feed requires an assessment of health risks and environmental effect (Araki and Ishii, 2015).

At present, there are no reports on the application of CRISPR in manipulating seed vigor in plants. Genome-editing techniques represent a promising tool for manipulating the accumulation of proteins associated with seed vigor in a seed-specific manner and should greatly reduce the time needed to obtain valuable crop varieties. Thus, the creation of such transgenic seeds and their subsequent application in agriculture is crucial for better feeding a rapidly growing population in a changing climate.

Seed quality is the basis of agricultural production. Highquality seeds are an unremitting pursuit for every seed producer. GM technology is an effective, economical and sustainable way to improve seed vigor, change seed color or shape, or boost nutrient components and other agronomic traits for crops. The application of GM technology will sharply change the face of agriculture.

\section{AUTHOR CONTRIBUTIONS}

WW and XH conceived the article. FN and XW collected references and analyzed the data. XW, FN, and WW revised the manuscript. All authors contributed in manuscript writing, and approved the final manuscript.

\section{FUNDING}

The National Natural Science Foundation of China (31371543 to WW); the Program for Innovative Research Team (in Science and Technology) in University of Henan Province (15IRTSTHN015 to $\mathrm{WW}$ ).

Araújo, S. S., Paparella, S., Dondi, D., Bentivoglio, A., Carbonera, D., and Balestrazzi, A. (2016). Physical methods for seed invigoration: advantages and challenges in seed technology. Front. Plant Sci. 7:646. doi: 10.3389/fpls.2016. 00646

Bouché, N., Fait, A., Bouchez, D., Moller, S. G., and Fromm, H. (2003). Mitochondrial succinic-semialdehyde dehydrogenase of the gammaaminobutyrate shunt is required to restrict levels of reactive oxygen intermediates in plants. Proc. Natl. Acad. Sci. U.S.A. 100, 6843-6848. doi: $10.1073 /$ pnas. 1037532100 
Bueso, E., Ibañez, C., Sayas, E., Muñoz-Bertomeu, J., Gonzalez-Guzmán, M., Rodriguez, P. L., et al. (2014). A forward genetic approach in Arabidopsis thaliana identifies a RING-type ubiquitin ligase as a novel determinant of seed longevity. Plant Sci. 21, 110-116. doi: 10.1016/j.plantsci.2013.11.004

Catusse, J., Meinhard, J., Job, C., Strub, J. M., Fischer, U., Pestsova, E., et al. (2011). Proteomics reveals potential biomarkers of seed vigor in sugarbeet. Proteomics 11, 1569-1580. doi: 10.1002/pmic.201000586

Catusse, J., Strub, J. M., Job, C., Van Dorsselaer, A., and Job, D. (2008). Proteomewide characterization of sugarbeet seed vigor and its tissue specific expression. Proc. Natl. Acad. Sci. U.S.A. 105, 10262-10267. doi: 10.1073/pnas.0800585105

Châtelain, E., Hundertmark, M., Leprince, O., Le Gall, S., Satour, P., DelignyPenninck, S., et al. (2012). Temporal profiling of the heat-stable proteome during late maturation of Medicago truncatula seeds identifies a restricted subset of late embryogenesis abundant proteins associated with longevity. Plant Cell Environ. 35, 1440-1455. doi: 10.1111/j.1365-3040.2012.02501.x

Châtelain, E., Satour, P., Laugier, E., Ly Vu, B., Payet, N., Rey, P., et al. (2013). Evidence for participation of the methionine sulfoxide reductase repair system in plant seed longevity. Proc. Natl. Acad. Sci. U.S.A. 110, 3633-3638. doi: 10. 1073/pnas. 1220589110

Chen, H., Chu, P., Zhou, Y., Li, Y., Liu, J., Ding, Y., et al. (2012). Overexpression of AtOGG1, a DNA glycosylase/AP lyase, enhances seed longevity and abiotic stress tolerance in Arabidopsis. J. Exp. Bot. 63, 4107-4121. doi: 10.1093/jxb/ ers093

Chu, P., Chen, H., Zhou, Y., Li, Y., Ding, Y., Jiang, L., et al. (2012). Proteomic and functional analyses of Nelumbo nucifera annexins involved in seed thermotolerance and germination vigor. Planta 235, 1271-1288. doi: 10.1007/ s00425-011-1573-y

Clarke, S. (2003). Aging as war between chemical and biochemical processes: protein methylation and the recognition of age-damaged proteins for repair. Ageing Res. Rev. 2, 263-285. doi: 10.1016/S1568-1637(03)00011-4

Clerkx, E. J. M., El-Lithy, M. E., Vierling, E., Ruys, G. J., Blankestijn-De Vries, H., Groot, S. P. C., et al. (2004). Analysis of natural allelic variation of Arabidopsis seed germination and seed longevity traits between the accessions Landsberg erecta and Shakdara, using a new recombinant inbred line population. Plant Physiol. 135, 432-443. doi: 10.1104/pp.103.036814

Cui, K. H., Peng, S. B., Xing, Y. Z., Xu, C. G., Yu, S. B., and Zhang, Q. (2002). Molecular dissection of seedling-vigour and associated physiological traits in rice. Theor. Appl. Genet. 105, 745-753. doi: 10.1007/s00122-002-0908-2

Devaiah, S. P., Pan, X., Hong, Y., Roth, M., Welti, R., and Wang, X. (2007). Enhancing seed quality and viability by suppressing phospholipase D in Arabidopsis. Plant J. 50, 950-957. doi: 10.1111/j.1365-313X.2007.03103.x

Gallardo, K., Job, C., Groot, S. P. C., Puype, M., Demol, H., Vandekerckhove, J., et al. (2001). Proteomic analysis of Arabidopsis seed germination and priming. Plant Physiol. 126, 835-848. doi: 10.1104/pp.126.2.835

Galpaz, N., and Reymond, M. (2010). Natural variation in Arabidopsis thaliana revealed a genetic network controlling germination under salt stress. PLOS ONE 5:e15198. doi: 10.1371/journal.pone.0015198

Guan, M., Møller, I. S., and Schjoerring, J. K. (2015). Two cytosolic glutamine synthetase isoforms play specific roles for seed germination and seed yield structure in Arabidopsis. J. Exp. Bot. 66, 203-212. doi: 10.1093/jxb/ eru411

Han, Z., Ku, L., Zhang, Z., Zhang, J., Guo, S., Liu, H., et al. (2014). QTLs for seed vigor-related traits identified in maize seeds germinated under artificial aging conditions. PLoS ONE 9:e92535. doi: 10.1371/journal.pone.0092535

Helm, K. W., Petersen, N. S., and Abernethy, R. H. (1989). Heat shock response of germinating embryos of wheat: effects of imbibition time and seed vigor. Plant Physiol. 90, 598-605. doi: 10.1104/pp.90.2.598

Hundertmark, M., Buitink, J., Leprince, O., and Hincha, D. K. (2011). The reduction of seed-specific dehydrins reduces seed longevity in Arabidopsis thaliana. Seed Sci. Res. 21, 165-173. doi: 10.1017/S0960258511000079

Kaur, H., Petla, B. P., Kamble, N. U., Singh, A., Rao, V., Salvi, P., et al. (2015). Differentially expressed seed aging responsive heat shock protein OsHSP18.2 implicates in seed vigor, longevity and improves germination and seedling establishment under abiotic stress. Front. Plant Sci. 6:713. doi: 10.3389/fpls. 2015.00713

Khatodia, S., Bhatotia, K., Passricha, N., Khurana, S. M. P., and Tuteja, N. (2016). The CRISPR/Cas genome-editing tool: application in improvement of crops. Front. Plant Sci. 7:506. doi: 10.3389/fpls.2016.00506
Kibinza, S., Vinel, D., Côme, D., Bailly, C., and Corbineau, F. (2006). Sunflower seed deterioration as related to moisture content during ageing, energy metabolism and active oxygen species scavenging. Physiol. Plant. 128, 496-506. doi: 10.1111/j.1399-3054.2006.00771.x

Kong, L., Huo, H., and Mao, P. (2015). Antioxidant response and related gene expression in aged oat seed. Front. Plant Sci. 6:158. doi: 10.3389/fpls.2015.00158

Lee, J., Welti, R., Roth, M., Schapaugh, W. T., Li, J., and Trick, H. N. (2012). Enhanced seed viability and lipid compositional changes during natural ageing by suppressing phospholipase $\mathrm{D} \alpha$ in soybean seed. Plant Biotechnol. J. 10, 164-173. doi: 10.1111/j.1467-7652.2011.00650.x

Lee, Y. P., Baek, K. H., Lee, H. S., Kwak, S. S., Bang, J. W., and Kwon, S. Y. (2010). Tobacco seeds simultaneously over-expressing $\mathrm{Cu} / \mathrm{Zn}$-superoxide dismutase and ascorbate peroxidase display enhanced seed longevity and germination rates under stress conditions. J. Exp. Bot. 61, 2499-2506. doi: 10.1093/jxb/ erq085

Lellis, A. D., Allen, M. L., Aertker, A. W., Tran, J. K., Hillis, D. M., Harbin, C. R., et al. (2010). Deletion of the eIFiso4G subunit of the Arabidopsis eIFiso4F translation initiation complex impairs health and viability. Plant Mol. Biol. 74, 249-263. doi: 10.1007/s11103-010-9670-z

Liu, J., Zhou, J., and Xing, D. (2012). Phosphatidylinositol 3-kinase plays a vital role in regulation of rice seed vigor via altering NADPH oxidase activity. PLOS ONE 7:e33817. doi: 10.1371/journal.pone.0033817

Lowenson, J. D., and Clarke, S. (1992). Recognition of D-aspartyl residues in polypeptides by the erythrocyte L-isoaspartyl/D-aspartyl protein methyltransferase. Implications for the repair hypothesis. J. Biol. Chem. 267, 5985-5995.

Macovei, A., Balestrazzi, A., Confalonieri, M., Buttafava, A., and Carbonera, D. (2011a). The TFIIS and TFIIS-like genes from Medicago truncatula are involved in oxidative stress response. Gene 470, 20-30. doi: 10.1016/j.gene.2010.09.004

Macovei, A., Balestrazzi, A., Confalonieri, M., Faé, M., and Carbonera, D. (2011b). New insights on the barrel medic MtOGG1 and MtFPG functions in relation to oxidative stress response in planta and during seed imbibition. Plant Physiol. Biochem. 49, 1040-1050. doi: 10.1016/j.plaphy.2011.05.007

Macovei, A., Gill, S. S., and Tuteja, N. (2012). microRNAs as promising tools for improving stress tolerance in rice. Plant Signal. Behav. 7, 1296-1301. doi: $10.4161 /$ psb. 21586

Manfre, A. J., LaHatte, G. A., Climer, C. R., and Marcotte, W. R. (2009). Seed dehydration and the establishment of desiccation tolerance during seed maturation is altered in the Arabidopsis thaliana mutant atem6-1. Plant Cell Physiol. 50, 243-253. doi: 10.1093/pcp/pcn 185

Manfre, A. J., Lanni, L. M., and Marcotte, W. R. (2006). The Arabidopsis group 1 late embryogenesis abundant protein ATEM6 is required for normal seed development. Plant Physiol. 140, 140-149. doi: 10.1104/pp.105.072967

Miura, K., Lin, S. Y., Yano, M., and Nagamine, T. (2002). Mapping quantitative trait loci controlling seed longevity in rice (Oryza sativa L.). Theor. Appl. Genet. 104, 981-986. doi: 10.1007/s00122-002-0872-x

Mudgett, M. B., and Clarke, S. (1993). Characterization of plant L-isoaspartyl methyltransferases that may be involved in seed survival: purification, cloning, and sequence analysis of the wheat germ enzyme. Biochemistry 32, 11100-11111. doi: 10.1021/bi00092a020

Mudgett, M. B., and Clarke, S. (1994). Hormonal and environmental responsiveness of a developmentally regulated protein repair 1-isoaspartyl methyltransferase in wheat. J. Biol. Chem. 269, 25605-25612.

Müller, K., Carstens, A. C., Linkies, A., Torres, M. A., and Leubner-Metzger, G. (2009). The NADPH-oxidase AtrbohB plays a role in Arabidopsis seed after ripening. New Phytol. 184, 885-897. doi: 10.1111/j.1469-8137.2009.03005.x

Nagel, M., Navakode, S., Scheibal, V., Baum, M., Nachit, M., Röder, M. S., et al. (2014). The genetic basis of durum wheat germination and seedling growth under osmotic stress. Biol. Plant. 58, 681-688. doi: 10.1007/s10535-014-0436-3

Ogé, L., Bourdais, G., Bove, J., Collet, B., Godin, B., Granier, F., et al. (2008). Protein repair L-isoaspartyl methyltransferase 1 is involved in both seed longevity and germination vigor in Arabidopsis. Plant Cell 20, 3022-3037. doi: 10.1105/tpc. 108.058479

Parkhey, S., Naithani, S. C., and Keshavkant, S. (2012). ROS production and lipid catabolism in desiccating Shorea robusta seeds during aging. Plant Physiol. Biochem. 57, 261-267. doi: 10.1016/j.plaphy.2012.06.008

Petla, B. P., Kamble, N. U., Kumar, M., Verma, P., Ghosh, S., Singh, A., et al. (2016). Rice PROTEIN 1-ISOASPARTYL METHYLTRANSFERASE isoforms 
differentially accumulate during seed maturation to restrict deleterious isoAsp and reactive oxygen species accumulation and are implicated in seed vigor and longevity. New Phytol. 211, 627-645. doi: 10.1111/nph.13923

Prieto-Dapena, P., Castano, R., Almoguera, C., and Jordano, J. (2006). Improved resistance to controlled deterioration in transgenic seeds. Plant Physiol. 142, 1102-1112. doi: 10.1104/pp.106.087817

Rajjou, L., Duval, M., Gallardo, K., Catusse, J., Bally, J., Job, C., et al. (2012). Seed germination and vigor. Annu. Rev. Plant Biol. 63, 507-533. doi: 10.1146/ annurev-arplant-042811-105550

Rajjou, L., Lovigny, Y., Groot, S. P. C., Belghazi, M., Job, C., and Job, D. (2008). Proteome-wide characterization of seed aging in Arabidopsis: a comparison between artificial and natural aging protocols. Plant Physiol. 148, 620-641. doi: $10.1104 /$ pp.108.123141

Ratajczak, E., Małecka, A., Bagniewska-Zadworna, A., and Kalemba, E. M. (2015). The production, localization and spreading of reactive oxygen species contributes to the low vitality of long-term stored common beech (Fagus sylvatica L.) seeds. J. Plant Physiol. 174, 147-156. doi: 10.1016/j.jplph.2014.08. 021

Revilla, P., Butrón, A., Rodríguez, V. M., Malvar, R. A., and Ordás, A. (2009). Identification of genes related to germination in aged maize seed by screening natural variability. J. Exp. Bot. 60, 4151-4157. doi: 10.1093/jxb/erp249

Roqueiro, G., Facorro, G. B., Huarte, M. G., Rubín de Celis, E., and Garcia, F. (2010). Effects of photooxidation on membrane integrity in Salix nigra seeds. Ann. Bot. 105, 1027-1034. doi: 10.1093/aob/mcq067

Sattler, S. E., Gilliland, L. U., Magallanes-Lundback, M., Pollard, M., and DellaPenna, D. (2004). Vitamin E is essential for seed longevity and for preventing lipid peroxidation during germination. Plant Cell 16, 1419-1432. doi: 10.1105/tpc.021360

Seo, Y. S., Kim, E. Y., and Kim, W. T. (2011). The Arabidopsis sn-1-specific mitochondrial acylhydrolase AtDLAH is positively correlated with seed viability. J. Exp. Bot. 62, 5683-5698. doi: 10.1007/s11103-010-9670-z

Shin, J. H., Kim, S. R., and An, G. (2009). Rice aldehyde dehydrogenase7 is needed for seed maturation and viability. Plant Physiol. 149, 905-915. doi: 10.1104/pp. 108.130716

Stacy, R. A., Nordeng, T. W., Culiáñez-Macià, F. A., and Aalen, R. B. (1999). The dormancy-related peroxiredoxin anti-oxidant, PER1, is localized to the nucleus of barley embryo and aleurone cells. Plant J. 19, 1-8. doi: 10.1046/j.1365-313X. 1999.00488.x

Sun, Q., Wang, J., and Sun, B. (2007). Advances on seed vigor physiological and genetic mechanisms. Agric. Sci. China 6, 1060-1066. doi: 10.1016/S16712927(07)60147-3

Suzuki, Y., and Matsukura, U. (1997). Lipoxygenase activity in maturing and germination rice seeds with and without lipoxygenase- 3 in mature seeds. Plant Sci. 125, 119-126. doi: 10.1016/S0168-9452(97)00061-7

Talai, S., and Sen-Mandi, S. (2010). Seed vigour-related DNA marker in rice shows homology with acetyl CoA carboxylase gene. Acta Physiol. Plant. 32, 153-167. doi: 10.1007/s11738-009-0392-2

Thapar, N., Kim, A. K., and Clarke, S. (2001). Distinct patterns of expression but similar biochemical properties of protein L-isoaspartyl methyltransferase in higher plants. Plant Physiol. 125, 1023-1035. doi: 10.1104/pp.125.2.1023

Vandecasteele, C., Teulat-Merah, B., Morère-Le Paven, M. C., Leprince, O., Ly Vu, B., Viau, L., et al. (2011). Quantitative trait loci analysis reveals a correlation between the ratio of sucrose/raffinose family oligosaccharides and seed vigour in Medicago truncatula. Plant Cell Environ. 34, 1473-1487. doi: 10.1111/j.13653040.2011.02346.x

Vanderauwera, S., Suzuki, N., Miller, G., van de Cotte, B., Morsa, S., Ravanat, J. L., et al. (2011). Extranuclear protection of chromosomal DNA from oxidative stress. Proc. Natl. Acad. Sci. U.S.A. 108, 1711-1716. doi: 10.1073/pnas. 1018359108

Ventura, L., Donà, M., Macovei, A., Carbonera, D., Buttafava, A., Mondoni, A., et al. (2012). Understanding the molecular pathways associated with seed vigor. Plant Physiol. Biochem. 60, 196-206. doi: 10.1016/j.plaphy.2012.07.031

Verma, P., Kaur, H., Petla, B. P., Rao, V., Saxena, S. C., and Majee, M. (2013). PROTEIN L-ISOASPARTYL METHYLTRANSFERASE2 is differentially expressed in chickpea and enhances seed vigor and longevity by reducing abnormal isoaspartyl accumulation predominantly in seed nuclear proteins. Plant Physiol. 161, 1141-1157. doi: 10.1104/pp.112.206243

Wang, L., Ma, H., Song, L., Shu, Y., and Gu, W. (2012). Comparative proteomics analysis reveals the mechanism of pre-harvest seed deterioration of soybean under high temperature and humidity stress. J. Proteomics 75, 2109-2127. doi: 10.1016/j.jprot.2012.01.007

Wang, R., Shen, W. B., Liu, L., Jiang, L., Zhai, H., and Wan, J. (2008). Prokaryotic expression, purification and characterization of a novel rice seed lipoxygenase gene OsLOX1. Rice Sci. 15, 88-94. doi: 10.1016/S1672-6308(08)60025-6

Wang, Y. Y., Hecker, A. G., and Hauser, B. A. (2014). The APX4 locus regulates seed vigor and seedling growth in Arabidopsis thaliana. Planta 239, 909-919. doi: 10.1007/s00425-014-2025-2

Waterworth, W. M., Masnavi, G., Bhardwaj, R. M., Jiang, Q., Bray, C. M., and West, C. E. (2010). A plant DNA ligase is an important determinant of seed longevity. Plant J. 63, 848-860. doi: 10.1111/j.1365-313X.2010.04285.x

Wei, Y. D., Xu, H. B., Diao, L. R., Zhu, Y. S., Xie, H. G., Cai, Q. H., et al. (2015). Protein repair L-isoaspartyl methyltransferase 1 (PIMT1) in rice improves seed longevity by preserving embryo vigor and viability. Plant Mol. Biol. 89, 475-492. doi: 10.1007/s11103-015-0383-1

Williams, B., and Tsang, A. (1991). A maize gene expressed during embryogenesis is abscisic acid-inducible and highly conserved. Plant Mol. Biol. 1991, 919-923. doi: 10.1007/BF00015086

Wu, X., Liu, H., Wang, W., Chen, S., Hu, X., and Li, C. (2011). Proteomic analysis of seed viability in maize. Acta Physiol. Plant. 33, 181-191. doi: 10.1007/s11738010-0536-4

Xi, D. M., Liu, W. S., Yang, G. D., Wu, C. A., and Zheng, C. C. (2010). Seed-specific overexpression of antioxidant genes in Arabidopsis enhances oxidative stress tolerance during germination and early seedling growth. Plant Biotechnol. J. 8, 796-806. doi: 10.1111/j.1467-7652.2010.00509.x

Xin, X., Tian, Q., Yin, G., Chen, X., Zhang, J., Ng, S., et al. (2014). Reduced mitochondrial and ascorbate-glutathione activity after artificial ageing in soybean seed. J. Plant Physiol. 171, 140-147. doi: 10.1016/j.jplph.2013.09.016

Xu, Q., Belcastro, M. P., Villa, S. T., Dinkins, R. D., Clarke, S. G., and Downie, A. B. (2004). A second protein L-isoaspartyl methyltransferase gene in Arabidopsis produces two transcripts whose products are sequestered in the nucleus. Plant Physiol. 136, 2652-2664. doi: 10.1104/pp.104.046094

Yacoubi, R., Job, C., Belghazi, M., Chaibi, W., and Job, D. (2011). Toward characterizing seed vigor in alfalfa through proteomic analysis of germination and priming. J. Proteome Res. 10, 3891-3903. doi: 10.1021/pr101274f

Yacoubi, R., Job, C., Belghazi, M., and Job, D. (2013). Proteomic analysis of the enhancement of seed vigour in osmoprimed alfalfa seeds germinated under salinity stress. Seed Sci. Res. 23, 99-110. doi: 10.1017/S0960258513000093

Yin, G., Xin, X., Song, C., Chen, X., Zhang, J., Wu, S., et al. (2014). Activity levels and expression of antioxidant enzymes in the ascorbate-glutathione cycle in artificially aged rice seed. Plant Physiol. Biochem. 80, 1-9. doi: 10.1016/j.plaphy. 2014.03.006

Zhou, Y., Chen, H., Chu, P., Li, Y., Tan, B., Ding, Y., et al. (2012a). NnHSP17.5, a cytosolic class II small heat shock protein gene from Nelumbo nucifera, contributes to seed germination vigor and seedling thermotolerance in transgenic Arabidopsis. Plant Cell Rep. 31, 379-389. doi: 10.1007/s00299-0111173-0

Zhou, Y., Chu, P., Chen, H., Li, Y., Liu, J., Ding, Y., et al. (2012b). Overexpression of Nelumbo nucifera metallothioneins $2 \mathrm{a}$ and 3 enhances seed germination vigor in Arabidopsis. Planta 235, 523-537. doi: 10.1007/s00425-011-1527-4

Conflict of Interest Statement: The authors declare that the research was conducted in the absence of any commercial or financial relationships that could be construed as a potential conflict of interest.

Copyright (c) $2017 \mathrm{Wu}$, Ning, Hu and Wang. This is an open-access article distributed under the terms of the Creative Commons Attribution License (CC BY). The use, distribution or reproduction in other forums is permitted, provided the original author(s) or licensor are credited and that the original publication in this journal is cited, in accordance with accepted academic practice. No use, distribution or reproduction is permitted which does not comply with these terms. 